\title{
๑ Relationships Between Managerial and Organizational Practices, Psychological Health at Work, and Quality of Care in Pediatric Oncology
}

Julien Lejeune, MD, $\mathrm{PhD}^{1,2}$; Severine Chevalier, $\mathrm{PhD}^{1}$; Evelyne Fouquereau, $\mathrm{PhD}^{1}$; Denis Chenevert, PhD³ Hélène Coillot, MMath ${ }^{1}$; Aurélien Binet, MD, PhD ${ }^{4}$; Nicolas Gillet, PhD ${ }^{1}$; René Mokounkolo, PhD ${ }^{1}$; Jean Michon, MD ${ }^{5}$; Sophie Dupont, PhD ${ }^{1}$; Petronela Rachieru, MD; Virginie Gandemer, MD, PhD7; and Philippe Colombat, MD, PhD ${ }^{1,2}$

QUESTION ASKED: What are the relationships between the psychological health of health care providers working in pediatric oncology and managerial and organizational determinants and with perceived quality of care?

SUMMARY ANSWER: Managerial (transformational leadership, perceived autonomy support) and organizational (organizational support, organizational justice, participatory approach) determinants were linked to psychological health of health care providers working in pediatric oncology. Health care providers' perception of quality of care was associated with their psychological health at work.

WHAT WE DID: Participants were 510 health care professionals working in French pediatric oncology centers. We performed regression analysis between psychological work health (quality of work life, work engagement, job satisfaction), managerial/organizational determinants, and perceived quality of care.

WHAT WE FOUND: In multiple regression analysis, a significant link was found between quality of work life and perceived organizational support $(\beta=.21 ; P<$ $.001)$, organizational justice $(\beta=.20 ; P<.001)$, and participatory approach $(\beta=.1 ; P<.002)$. In multiple regression analysis, perceived quality of care was linked to quality of work life $(\beta=.14 ; P<.001)$ and job satisfaction $(\beta=.29 ; P<.001)$.

BIAS, CONFOUNDING FACTORS: The fact that, to some, the managerial and organizational factors studied in our research are not major explanatory factors in multivariate studies suggests that other determinants may play a major role in the psychological health at work of pediatric oncology staff.

REAL-LIFE IMPLICATIONS: These results emphasize the importance of the role of managers and organizations in psychological work health of health care providers and also in the quality of patient care. They could inform health organizations, and in particular pediatric oncology departments, to strengthen their managerial practices to optimize both the well-being of health care staff and the quality of care of pediatric patients and their families. 


\section{(อ) Relationships Between Managerial and Organizational Practices, Psychological Health at Work, and Quality of Care in Pediatric Oncology}

Julien Lejeune, MD, $\mathrm{PhD}^{1,2}$; Severine Chevalier, $\mathrm{PhD}^{1}$; Evelyne Fouquereau, $\mathrm{PhD}^{1}$; Denis Chenevert, PhD³ Hélène Coillot, MMath ${ }^{1}$; Aurélien Binet, MD, PhD ; Nicolas Gillet, PhD ${ }^{1}$; René Mokounkolo, $\mathrm{PhD}^{1}$; Jean Michon, MD ${ }^{5}$; Sophie Dupont, PhD ${ }^{1}$; Petronela Rachieru, MD; ${ }^{6}$ Virginie Gandemer, MD, PhD; ; and Philippe Colombat, MD, PhD ${ }^{1,2}$

PURPOSE Psychological health at work for care providers is an important issue, because they are directly involved in quality of patient care. Managerial and organizational determinants have been found to be indicators of psychological health at work. The main objective of this study was to explore the relationships between the psychological health at work of pediatric oncology care workers with managerial and organizational determinants and with quality of care.

MATERIALS AND METHODS We performed regression analysis between psychological health at work (quality of work life [QWL], job satisfaction, and so on), managerial determinants (transformational leadership, perceived autonomy support), organizational determinants (organizational support, organizational justice, and participatory approach), and perceived quality of care.

RESULTS Participants were 510 health care professionals working in French pediatric oncology centers. No significant differences in the psychological health at work of the participants were found based on age, sex, length of employment, or professional discipline. In simple regression, significant associations were found between psychological health at work with all managerial and organizational determinants. In multiple regression, a significant link was found between $Q W L$ and perceived organizational support $(\beta=.21 ; P<.001)$, organizational justice $(\beta=.20, P<.001)$, and overall participatory approach $(\beta=.10 ; P<.02)$. Job satisfaction was also related to perceived organizational support $(\beta=.16 ; P<.01)$. Finally, perceived quality of care was linked to QWL $(\beta=.15 ; P<.01)$ and job satisfaction $(\beta=.30 ; P<.001)$.

CONCLUSION These results emphasize the importance of the role of managers and the organization in psychological health at work of health care providers and also in the quality of patient care

\section{JCO Oncol Pract 16:e1112-e1119. @ 2020 by American Society of Clinical Oncology}

Creative Commons Attribution Non-Commercial No Derivatives 4.0 License (c) $($ ) ()

\section{INTRODUCTION}

Psychological health at work (PHW) has been defined as a 2-dimensional construct involving a low level of psychological distress and a high level of well-being. ${ }^{1}$ For many years, psychological health has been studied in many professional fields because of its connection with various attitudes and behaviors at work. ${ }^{2}$ In the field of health care, psychological health is often studied in its negative aspects (eg, burnout) and rarely its more positive aspects. In oncology, the frequency of professional exhaustion/burnout has been studied for $>20$ years, ${ }^{3-5}$ whereas the PHW of health care providers (eg, physicians, nurses, allied health professionals) is a more recent research topic.

In the literature, the main studies devoted to PHW of health care providers and its determinants are based on "magnet hospitals." These are hospitals that have developed an organizational and managerial model that attracts and retains nurses. ${ }^{6}$ They include features such as a "flat" organizational nursing structure, unitbased decision making, staff nurses included in the decision-making team, autonomy, and control over patient care. Comparative studies have found that health workers in magnet hospitals have better quality of work life (QWL), greater work engagement, and a better assessment of the quality of patient care than those in conventional hospitals. ${ }^{7}$ Moreover, magnet hospitals report lower absenteeism and staff turnover and better quality of care evaluated by patients. ${ }^{8}$ Despite the large number of studies on magnet hospitals, few have specifically focused on the managerial and organizational determinants of psychological

\section{ASCO}


health at work, particularly in the field of oncology. And yet, in other professional areas, the main indicators of PHW, including QWL, work engagement, and job satisfaction, have been demonstrated to be influenced by managerial and organizational factors. ${ }^{9-11}$

Management style, and more broadly the relationship with employees, has been identified as a major predictor of nurses' QWL. ${ }^{12}$ For example, perceived autonomy support provides a meaningful rationale for performing tasks, emphasizes choice rather than control, and acknowledges nurses' feelings and views. ${ }^{13}$ When care providers perceive their supervisors as fair and autonomy supportive, they respond positively to their work, reporting greater work satisfaction and organizational identification, and show improved job performance. ${ }^{14,15}$ Managers who exhibit autonomy-supportive behaviors facilitate the development of subordinates' well-being, work satisfaction, and job performance. ${ }^{16,17}$ Transformational leadership (defined as a style of management in which the manager inspires employees, considers their individual needs and feelings, and encourages them to work together $)^{18}$ can also influence PHW. For example, in a large sample of onco-hematology nurses, Gillet et $\mathrm{al}^{16}$ found a relationship between transformational leadership and QWL/work engagement.

Organizational determinants, such as perceived organizational support and organizational justice, have also been found to be indicators of PHW. Perceived organizational support refers to employees' beliefs regarding the extent to which their organization values their contributions and cares about their well-being ${ }^{19}$; it has been found to lead to various positive outcomes, including job satisfaction and job performance. ${ }^{17,20,21}$ Organizational justice refers to the way individuals perceive their treatment at work. ${ }^{22}$ Organizational justice is positively linked to $Q W L^{23}$ and negatively related to negative emotional states, perceived stress, depression, and anxiety. ${ }^{24,25}$ Organizational justice has been shown to play a mediating role in the relationship between transformational leadership and the QWL of oncology nurses. ${ }^{16}$

In addition to the factors commonly reported in the literature, some studies focus on innovative approaches in the managerial and organizational domains. Innovative managerial or organizational practices in oncology have been shown to lead to improvements both in the care providers' PHW and in the quality of patient care. ${ }^{26,27}$ The specific participatory approach (PA) adopted in the French health system is an organizational model that fosters good communication and teamwork among oncology health workers. It was first introduced in the 1990s, when a think-tank on treatment and palliative care concluded that improving the quality of the care providers' life at work would lead to better overall care of patients and their families. The importance of this approach in the French health care system has been strengthened by making it mandatory in all departments involving palliative care. The PA is based on 2 major lines of action: enhancing team communication and implementing a project approach. Communication is developed through various means (multidisciplinary team meetings, in-service training, team support meetings). Multidisciplinary team meetings bring together professionals from different clinical disciplines to discuss the overall management of patients or analyze morbidity and mortality reviews. In-service training ensures that all members of the care team receive comparable and consistent training; it provides opportunities for the team members to talk about their experiences, particularly for those who do not often express themselves. It also promotes interprofessional relations as part of team building. Team support meetings, led by a psychotherapist, are set up to debrief care staff in crisis situations. Management meetings bring together physicians and nurse managers to make joint decisions about managerial issues, such as the functioning of the department and recruitment. The project approach involves identifying a problem or a need and setting up multidisciplinary working groups to put forward and discuss ways of dealing with it. Through this approach, care providers are recognized, valued, and empowered, and it has been shown to improve the QWL of onco-hematology staff. ${ }^{28}$

Overall, certain managerial and organizational determinants have been shown to be linked to PHW of health care providers. However, to the best of our knowledge, these links have not been specifically studied in the domain of pediatric oncology. Most published articles refer to workrelated stress or burnout. ${ }^{5,29,30}$ However, to increase the quality of patient care in oncology, it is essential to look at the care providers' relationship with their professional activity and in particular their PHW. The first objective of this study was thus to explore the relationships between the PHW of pediatric oncology care workers and ${ }^{1}$ managerial determinants and $^{2}$ organizational determinants. The second objective was to analyze the link between PHW and the quality of care perceived by pediatric oncology care providers.

\section{MATERIALS AND METHODS}

\section{Study Design}

Following the agreement of the French Society of Pediatric Oncology (Société Française de Lutte contre les Cancers et les Leucémies de l'Enfant et de l'Adolescent), 30 specialized pediatric cancer centers in France were contacted. Of these, 25 agreed to participate in the study. In each of these 25 centers, a contact person was identified, generally the nurse manager, who distributed the paper questionnaires to members of the health care team. These questionnaires were returned anonymously in a sealed envelope. The clinical researcher leading the study sent regular reminders to the contact person.

\section{Participants}

Participants were 510 health care professionals working in French pediatric oncology centers. They included 
oncologists ( $n=64)$, nurses ( $n=261)$, and allied health staff $(n=185)$. They provided information about a range of demographic and job-related characteristics, including age, sex, professional discipline, and length of time working in oncology.

\section{Measures}

PHW was assessed through various indicators. QWL was assessed with the 16-item questionnaire developed by Elizur and Shye ${ }^{9}(\alpha=.91)$. Work engagement was measured using the 9-item version of the Utrecht Work Engagement Scale $^{10}(\alpha=.92)$. Job satisfaction ${ }^{11}$ was evaluated with a single item ("In your current job, are you satisfied?").

Managerial determinants of PHW were transformational leadership and perceived autonomy support. The Global Transformational Leadership scale ${ }^{31}$ was used to assess care providers' perceptions of transformational leadership $(\alpha=.82)$. Perceived autonomy support was assessed with the French version of the scale used by Moreau and Mageau $^{32}(\alpha=.94)$.

Organizational determinants of PHW were organizational support, organizational justice, and participatory approach. Perceived organizational support was measured with an 8item version of the Perceived Organizational Support Scale developed by Eisenberger et $\mathrm{al}^{19}(\alpha=.82)$. Organizational justice was assessed using the justice scale developed by Niehoff and Moorman ${ }^{33}(\alpha=.93)$. The participatory approach was assessed with the scale developed by Pronost et $\mathrm{al}^{28}$ which includes 4 dimensions (multiprofessional team meetings, in-service training, team support meetings, project approach). Perceived quality of patient care was evaluated with a single item ("In your current job are you satisfied with the quality of patient care?").

\section{Analysis}

Data were analyzed using SPSS 25 statistical software (version 25.0, SPSS Inc, USA). Statistical significance was set at the $P<.05$ level. Descriptive statistics for demographic factors included the calculation of relative frequencies (percentages) and measures of central tendency (means) and dispersion (standard deviations) for quantitative variables. Links between PHW and demographic factors were analyzed with analysis of variance (ANOVA) and Student $t$ test. ANOVA was performed to analyze differences between oncology centers. A global score was recorded for QWL, work engagement, transformational leadership, perceived autonomy support, perceived organizational support, and PA, with the highest values corresponding to the highest levels observed for each indicator. Using single and multiple regression analysis, several models were used to assess the link between psychological health at work and managerial/ organizational determinants.

Model 1: Dependent variable (DV): QWL; independent variable (IV): managerial and/or organizational determinants.
Model 2: DV: Work engagement; IV: managerial and/or organizational determinants.

Model 3: DV: Job satisfaction; IV: managerial and/or organizational determinants.

Relationships between the psychological health at work and quality of care were analyzed with single and multiple regression where perceived quality of care was considered as DV and QWL, work engagement, and job satisfaction as IVs.

\section{RESULTS}

\section{Demographic Factors and PHW of Health Care Providers}

In total, 510 care providers participated in our study, with a homogeneous age distribution but a strong preponderance of nurses (Table 1). No significant differences in the psychological health at work of the participants were found based on age, sex, length of employment, or professional discipline (oncologist, nurse, allied health worker; Table 1). We found significant differences between centers in the QWL, engagement, and job satisfaction of their care staff (Data Supplement).

TABLE 1. Demographic and Job-Related Variables of Participants

\begin{tabular}{|c|c|c|c|}
\hline Demographic & No. & $\%$ & Mean (SD) \\
\hline \multicolumn{4}{|l|}{ Sex } \\
\hline Man & 39 & 7.6 & \\
\hline Woman & 470 & 92.2 & \\
\hline Not available & 1 & 0.2 & \\
\hline \multicolumn{4}{|l|}{ Age, years } \\
\hline$<30$ & 180 & 35.3 & $26.14(2.03)$ \\
\hline $30-40$ & 195 & 38.2 & $34.08(3.30)$ \\
\hline$>40$ & 130 & 25.5 & $49.33(6.42)$ \\
\hline Not available & 5 & 1.0 & \\
\hline \multicolumn{4}{|c|}{ Professional discipline } \\
\hline Medical & 64 & 12.5 & \\
\hline Nurses & 375 & 73.6 & \\
\hline Allied health & 71 & 13.9 & \\
\hline \multicolumn{4}{|c|}{ Years of experience } \\
\hline$<1$ & 38 & 7.5 & $0.36(0.21)$ \\
\hline $1-3$ & 153 & 30.0 & $2.00(0.80)$ \\
\hline$>3$ & 311 & 61.0 & $11.52(8.20)$ \\
\hline Not available & 8 & 1.6 & \\
\hline \multicolumn{4}{|l|}{ Employment } \\
\hline Full time & 385 & 75.5 & \\
\hline Part time & 124 & 24.3 & \\
\hline Not available & 1 & 0.2 & \\
\hline
\end{tabular}

Abbreviation: SD, standard deviation. 
Simple Regression Analyses of the Relationship Between PHW and Managerial Factors

Regression analyses indicated that QWL was associated with the managerial factors of transformational leadership $(\beta=.25 ; P<.001)$ and perceived autonomy support $(\beta=$ .30; $P<.001$ ). Job satisfaction was also related to transformational leadership $(\beta=.25 ; P<.001)$ and to perceived autonomy support $(\beta=.24 ; P<.001)$. Our results also revealed a significant relationship between work engagement and transformational leadership ( $\beta=$ $.16 ; P<.001)$ and perceived autonomy support $(\beta=.18$; $P<.001)$.

\section{Simple Regression Analyses of the Relationship Between PHW and Organizational Factors}

Overall QWL, as well as all its subdimensions, was also related to the organizational factors of organizational justice $(\beta=.37 ; P<.001)$, perceived organizational support $(\beta=$ .37; $P<.001)$, and global PA $(\beta=.27 ; P<.001)$. We also found that job satisfaction was related to organizational justice $(\beta=.28 ; P<.001)$, perceived organizational support $(\beta=.28 ; P<.001)$, and global PA $(\beta=.17 ; P<$ .001). Work engagement was linked to organizational justice $(\beta=.20 ; P<.001)$, perceived organizational support $(\beta=.14 ; P<.01)$, and global PA $(\beta=.17$; $P<.001)$.

\section{Multiple Regression Analyses of the Relationship Between PHW and Managerial/Organizational Factors}

In model 1, perceived organizational support $(\beta=.21 ; P<$ .001), organizational justice $(\beta=.20 ; P<.001)$, and global PA ( $\beta=.10 ; P<.02)$ contributed significantly to the prediction of QWL ( $R^{2}=0.2$; Table 2$)$. In model 2, no managerial or organizational determinants were linked with work engagement. In model 3 , perceived organizational support $(\beta=.15 ; P<.001)$ contributed significantly to the prediction of job satisfaction ( $R^{2}=0.13$; Table 2$)$.

\section{PHW and Quality of Care Perceived by Health Care Providers}

Simple regression analyses revealed that $\mathrm{QWL}(\beta=.24$; $P<.001)$, job satisfaction $(\beta=.34 ; P<.001)$, and work engagement $(\beta=.18 ; P<.001$ ) were significantly related to the quality of care perceived by care providers. Finally, a multiple regression analysis showed that $\mathrm{QWL}(\beta=.14$; $P<.001)$ and job satisfaction $(\beta=.29 ; P<.001)$ contributed significantly to the perceived quality of care $\left(R^{2}=\right.$ 0.14; Table 3).

\section{DISCUSSION}

We report here the first large-sample study, to our knowledge, to analyze the PHW of health care providers in pediatric oncology. The aims of this research were to analyze the influence of a number of managerial and organizational factors on the psychological health of care
TABLE 2. Multiple Regression Analysis Between Psychological Health at Work and Managerial/Organizational Factors

\begin{tabular}{|c|c|c|c|c|}
\hline Model & DV & IV & $\boldsymbol{\beta}$ & $P$ \\
\hline \multirow[t]{5}{*}{1} & QWL & TL & .13 & .055 \\
\hline & & PAS & .13 & .053 \\
\hline & & POS & .21 & $<.001$ \\
\hline & & OJ & .2 & $<.001$ \\
\hline & & Global PA & .1 & .02 \\
\hline \multirow[t]{5}{*}{2} & Work engagement & TL & .01 & .82 \\
\hline & & PAS & .09 & .22 \\
\hline & & POS & .003 & .94 \\
\hline & & OJ & .11 & .08 \\
\hline & & Global PA & .09 & .05 \\
\hline \multirow[t]{5}{*}{3} & Job satisfaction & TL & .06 & .41 \\
\hline & & PAS & .2 & .79 \\
\hline & & POS & .15 & $<.001$ \\
\hline & & OJ & .12 & .053 \\
\hline & & Global PA & .02 & .64 \\
\hline
\end{tabular}

Abbreviations: DV, dependent variable; IV, independent variable; OJ, organizational justice; PA, participatory approach; PAS, perceived autonomy support; POS, perceived organizational support; QWL, quality of work life; TL, transformational leadership.

providers and its links with their perception of quality of patient care.

Few studies have studied the correlations between PHW and the demographic or job characteristics of health care providers in pediatric oncology. In our study, we did not find any significant correlations between these factors, which is in line with the results of Bowden et $\mathrm{al}^{34}$ showing that demographic and job characteristics are not associated with work-related sources of stress in pediatric oncology. By contrast, our results are at odds with studies in pediatric oncology that found associations between burnout and number of years of experience ${ }^{35}$ and age. ${ }^{36}$ Future studies should therefore elucidate more precisely the role of these demographic factors and employment characteristics in the PHW of pediatric oncology staff.

Regression analysis revealed links between transformational leadership, perceived autonomy support, and the PHW of pediatric oncology care providers. The role of management style in care providers' attitudes and

TABLE 3. Multiple Regression Analysis Between Psychological Health at Work and Perceived Quality of Care

\begin{tabular}{llcc} 
DV & \multicolumn{1}{c}{ IV } & $\boldsymbol{\beta}$ & \multicolumn{1}{c}{$\boldsymbol{P}$} \\
\hline Perceived quality of care & QWL & .14 & $<.001$ \\
\cline { 2 - 4 } & Work engagement & .004 & .92 \\
\cline { 2 - 4 } & Job satisfaction & .29 & $<.001$
\end{tabular}

Abbreviations: DV, dependent variable; IV, independent variable; QWL, quality of work life. 
behaviors has been widely studied. ${ }^{37}$ In particular, some studies have shown that a climate of trust between managers and care providers is associated with a positive attitude of the latter, which can influence the implementation of safe behaviors and practices ${ }^{38}$ and avoids errors or accidents. ${ }^{39}$ In other words, these positive attitudes are associated not only with greater job satisfaction but also with improved performance. ${ }^{40}$ Our results confirm the explanatory power of some innovative managerial practices in the PHW of pediatric oncology staff, based notably on the individualized consideration of each member of the care team. It would be interesting to extend these findings by examining the effects of other managerial approaches in oncology, such as ethical leadership. ${ }^{41}$

In this study, organizational determinants were also related to the various indicators of PHW. Regression analysis revealed that perceived organizational support and organizational justice were linked to our indicators of psychological health at work. Several earlier studies emphasized the role of these relationships ${ }^{42}$ in PHW. However, our findings are the first, to our knowledge, to confirm the importance of these organizational factors in the psychological health at work of pediatric oncology staff. Finally, in addition to perceived organizational support and organizational justice, which has already been reported in the work psychology literature, the aim of our research was to investigate the link between a participatory approach and the PHW of pediatric oncology staff. The results of regression analysis revealed an association between the establishment of a participatory approach and the care providers' PHW. These findings extend the results of previous studies showing that a participatory approach improved the QWL of care staff in adult onco-hematology departments. ${ }^{28}$ Consequently, they confirm the interest and relevance of this participatory model in care teams. A validated scale should be developed to evaluate its implementation in health care departments.

In short, our results illustrate the importance of managerial and organizational factors in the psychological health of oncology health care providers. The scientific literature has often highlighted the link between psychological health and staff turnover or absenteeism, which are crucial issues for health organizations. In addition, the fact that some of the managerial and organizational factors studied in our research are not major explanatory factors in multivariate studies suggests that other determinants may play a major role in the psychological health of pediatric oncology staff.

\footnotetext{
AFFILIATIONS

${ }^{1}$ Qualipsy EE 1901, Université de Tours, Tours, France

${ }^{2}$ Service d'Onco-Hématologie Pédiatrique, Hôpital Clocheville, Tours, France

${ }^{3}$ Ecole des Hautes Etudes Commerciales, Montreal, Québec, Canada ${ }^{4}$ Service de Chirurgie Pédiatrique, Hôpital Clocheville, Tours, France ${ }^{5}$ Département de Pédiatrie, Institut Curie, Paris, France
}

Moreover, we found that health care providers' perception of quality of care was linked to their QWL and job satisfaction. Although the International Society of Pediatric Oncology has long recognized the importance of the psychological health of professionals working with sick children, ${ }^{30}$ this is the first study, to our knowledge, providing empirical evidence supporting this claim. Our results are in line with studies showing a link between burnout among oncology physicians and quality of care, through indicators such as medical errors, lack of empathy, and patients' satisfaction with their medical care. ${ }^{4}$ Overall, these results confirm the impact of psychological health at work on patient care. ${ }^{43}$

Despite their interest, the present results present limitations that should be addressed in future research. First, we used a single item to assess job satisfaction and perceived quality of care. Yet, it is well known that single-item measures tend to be more unreliable than multi-item measures and not as good at providing a complete content coverage of the construct under consideration. It would thus be interesting for future research to replicate the present results using more solid measurement scales. Second, we have analyzed $\mathrm{PHW}$ in different pediatric cancer centers, and we highlighted significant differences between centers. A multilevel analysis would have allowed us to take into account these significant differences between cancer centers. Unfortunately, because of a disparity in the percentage of responses between cancer centers, we were unable at this time to carry out this multilevel analysis. Third, we did not highlight significant differences between sex and indicators of PHW. But within our sample, the proportion of men is clearly under-represented and constitutes a limit. Future studies are therefore needed to study the link between sex and PHW.

The findings of this exploratory study have important implications for both practice and research. They emphasize the importance of the role of managers and the organization not only in health care providers' quality of life at work but also in the quality of patient care. They should enable health organizations, and in particular pediatric oncology departments, to strengthen their managerial practices to optimize both the well-being of health care staff and the quality of care of children and their families. Future studies testing integrative models should explore the psychological mechanisms underlying health care providers' quality of life at work and the consequences for the patients.

${ }^{6}$ Unité Douleur-Soins de Support-Soins Palliatifs, CHU Angers, Angers, France

${ }^{7}$ Service d'Onco-Hématologie Pédiatrique, CHU Hôpital Sud, Rennes, France 


\section{CORRESPONDING AUTHOR}

Julien Lejeune, Hopital Gatien de Clocheville, 49 Boulevard Béranger, Tours, Indre et Loire 37000, France; e-mail: j.lejeune@chu-tours.fr.

\section{SUPPORT}

Supported by the Fondation de France and CANCEN.

\section{AUTHORS' DISCLOSURES OF POTENTIAL CONFLICTS OF INTEREST AND DATA AVAILABILITY STATEMENT}

Disclosures provided by the authors and data availability statement (if applicable) are available with this article at DOI https://doi.org/10.1200/ JOP.19.00583.

\section{AUTHOR CONTRIBUTIONS}

Conception and design: Julien Lejeune, Severine Chevalier, Evelyne Fouquereau, Aurélien Binet, Nicolas Gillet, René Mokounkolo, Petronela Rachieru, Philippe Colombat

Administrative support: Aurélien Binet

Provision of study material or patients: Jean Michon, Virginie Gandemer Collection and assembly of data: René Mokounkolo, Jean Michon, Sophie Dupont

Data analysis and interpretation: Julien Lejeune, Severine Chevalier, Evelyne Fouquereau, Denis Chenevert, Hélène Coillot, Virginie Gandemer Manuscript writing: All authors

Final approval of manuscript: All authors

Accountable for all aspects of the work: All authors

\section{ACKNOWLEDGMENT}

We thank all the centers of the Sociéte Française de Lutte contre les Cancers et les Leucémies de l'Enfant et de l'Adolescent who participated in this study: Amiens (C. Devoldere, C. Douadi), Angers (I. Pellier, S. Mareni), Besançon (N. Cheikh, K. Ancelin-Chauvin), Bordeaux (Y. Perel, S. Sangare), Brest (L. Carausu, B. de Lapasse), Caen (O. Minckes, C. Langlois), Clermont-Ferrand (J. Kanold, M. Gaudio), Dijon (G. Couillault, A. Latroyes), Grenoble (D. Plantaz, F. Maxit), Lille CHU (W. Abouchalah, C. Letout), Limoges (C. Piguet, H. Nomme), Lyon (Y. Bertrand, A. Famery), Marseille (G. Michel, M. Guiraud), Nancy (C. Chastagner, M. C. Mirouf), Nantes (C. Thomas, K. Roux), Nice (C. Soler, P. Cozzi), Poitiers (F. Millot, R. Grollier), Reims (C. Pluchart, L. Lefort), Rennes (V. Gandemer, M. Boishu), Rouen (J. P. Vannier, O. Dupray), Strasbourg (P. Lutz, F. Meyer), Toulouse (I. Bertozzi-Salamon, M. L. Leygues), Tours (P. Blouin, S. Panneau), IGR Villejuif (D. Valteau-Couannet, P. Usubelli), Trousseau Paris (G. Leverger, V. Tanguy), Curie Paris (J. Michon, A. G. Briand). We also thank the Fondation de France and CANCEN who funded this study, and the national "Qualité de vie et cancer" platform.

\section{REFERENCES}

1. Keyes CLM: Complete mental health: An agenda for the 21st century, in Keyes CLM, Haidt J (eds): Flourishing: Positive Psychology and the Life Well-Lived. Washington, DC, American Psychological Association, 2003, pp 293-312

2. Harnois G, Gabriel P: Mental health and work: Impact, issues and good practices. Geneva, Switzerland, World Health Organisation/International Labour Organisation, 2000

3. Ramirez AJ, Graham J, Richards MA, et al: Burnout and psychiatric disorder among cancer clinicians. Br J Cancer 71:1263-1269, 1995

4. Shanafelt T, Dyrbye L: Oncologist burnout: Causes, consequences, and responses. J Clin Oncol 30:1235-1241, 2012

5. Mukherjee S, Beresford B, Glaser A, et al: Burnout, psychiatric morbidity, and work-related sources of stress in paediatric oncology staff: A review of the literature. Psychooncology 18:1019-1028, 2009

6. Aiken LH, Poghosyan L: Evaluation of "magnet journey to nursing excellence program" in Russia and Armenia. J Nurs Scholarsh 41:166-174, 2009

7. Lundstrom T, Pugliese G, Bartley J, et al: Organizational and environmental factors that affect worker health and safety and patient outcomes. Am J Infect Control 30:93-106, 2002

8. Stimpfel AW, Sloane DM, McHugh MD, et al: Hospitals known for nursing excellence associated with better hospital experience for patients. Health Serv Res 51 : 1120-1134, 2016

9. Elizur D, Shye S: Quality of work and its relation to quality of life. Appl Psychol 39:275-291, 1990

10. Schaufeli W, Bakker A: Utrecht Work Engagement Scale: Preliminary Manual. Utrecht, Occupational Health Psychology Unit, Utrecht University, 2003

11. Locke EA: The nature and causes of job satisfaction, in MD Dunette, ed: Handbook of Industrial and Organizational Psychology. Chicago, Rand McNally, 1976, pp 1297-1349

12. Knox S, Irving JA: Nurse manager perceptions of healthcare executive behaviors during organizational change. J Nurs Adm 27:33-39, 1997

13. Deci EL, Connel JP, Ryan RM: Self-determination in a work organization. J Appl Psychol 74:580-590, 1989

14. Gagné M, Deci EL: Self-determination theory and work motivation. J Organ Behav 26:331-362, 2005

15. St-Pierre I, Holmes D: The relationship between organizational justice and workplace aggression. J Adv Nurs 66:1169-1182, 2010

16. Gillet N, Fouquereau E, Bonnaud-Antignac A, et al: The mediating role of organizational justice in the relationship between transformational leadership and nurses' quality of work life: A cross-sectional questionnaire survey. Int J Nurs Stud 50:1359-1367, 2013

17. Gillet N, Colombat P, Michinov E, et al: Procedural justice, supervisor autonomy support, work satisfaction, organizational identification and job performance: The mediating role of need satisfaction and perceived organizational support. J Adv Nurs 69:2560-2571, 2013

18. Bass BM: The future of leadership in learning organizations. J Leadersh Stud 7:18-40, 2000

19. Eisenberger R, Huntington R, Hutchison S, et al: Perceived organizational support. J Appl Psychol 71:500-507, 1986

20. Sluss DM, Klimchak M, Holmes JJ: Perceived organizational support as a mediator between relational exchange and organizational identification. J Vocat Behav 73:457-464, 2008

21. Rhoades L, Eisenberger R: Perceived organizational support: A review of the literature. J Appl Psychol 87:698-714, 2002

22. Greenberg J: Organizational justice: Yesterday, today, and tomorrow. J Manage 16:399-432, 1990

23. Lam W, Chen Z: When I put on my service mask: Determinants and outcomes of emotional labor among hotel service providers according to affective event theory. Int J Hospit Manag 31:3-11, 2012

24. Kalimo R, Taris TW, Schaufeli WB: The effects of past and anticipated future downsizing on survivor well-being: An equity perspective. J Occup Health Psychol 8:91-109, 2003 
25. Spell C, Arnold T: A multi-level analysis of organizational justice climate, structure and employee mental health. J Manage 33:724-751, 2007

26. Johansen NJ, Saunders CM: Value-based care in the worldwide battle against cancer. Cureus 9:e1039, 2017

27. Tremblay D, Roberge D, Touati N, et al: Effects of interdisciplinary teamwork on patient-reported experience of cancer care. BMC Health Serv Res 17:218, 2017

28. Pronost AM, Le Gouge A, Leboul D, et al: Relationships between the characteristics of oncohematology services providing palliative care and the sociodemographic characteristics of caregivers using health indicators: Social support, perceived stress, coping strategies, and quality of work life. Support Care Cancer 20:607-614, 2012

29. Roth M, Morrone K, Moody K, et al: Career burnout among pediatric oncologists. Pediatr Blood Cancer 57:1168-1173, 2011

30. Spinetta JJ, Jankovic M, Masera G, et al: Optimal care for the child with cancer: A summary statement from the SIOP Working Committee on Psychosocial Issues in Pediatric Oncology. Pediatr Blood Cancer 52:904-907, 2009

31. Carless SA, Wearing AJ, Mann L: A short measure of transformational leadership. J Bus Psychol 14:389-405, 2000

32. Moreau E, Mageau G: The importance of perceived autonomy support for the psychological health and work satisfaction of health professionals: Not only supervisors count, colleagues too! Motiv Emot 36:268-286, 2012

33. Niehoff BP, Moorman RH: Justice as a mediator of the relationship between methods of monitoring and organizational citizenship behavior. Acad Manage J 36 : 527-556, 1993

34. Bowden MJ, Mukherjee S, Williams LK, et al: Work-related stress and reward: An Australian study of multidisciplinary pediatric oncology healthcare providers. Psychooncology 24:1432-1438, 2015

35. Liakopoulou M, Panaretaki I, Papadakis V, et al: Burnout, staff support, and coping in Pediatric Oncology. Support Care Cancer 16:143-150, 2008

36. Davis S, Lind BK, Sorensen C: A comparison of burnout among oncology nurses working in adult and pediatric inpatient and outpatient settings. Oncol Nurs Forum 40:E303-E311, 2013

37. Cummings G, Hayduk L, Estabrooks C: Mitigating the impact of hospital restructuring on nurses: The responsibility of emotionally intelligent leadership. Nurs Res 54:2-12, 2005

38. Aiken LH, Clarke SP, Sloane DM: Hospital restructuring: Does it adversely affect care and outcomes? J Nurs Adm 30:457-465, 2000

39. Aiken LH, Sochalski J, Lake ET: Studying outcomes of organizational change in health services. Med Care 35:NS6-NS18, 1997 (suppl 11)

40. Isla Díaz R, Díaz Cabrera D: Safety climate and attitude as evaluation measures of organizational safety. Accid Anal Prev 29:643-650, 1997

41. Storch J, Schick Makaroff K, Pauly B, et al: Take me to my leader: The importance of ethical leadership among formal nurse leaders. Nurs Ethics 20:150-157, 2013

42. Gershon RR, Karkashian CD, Grosch JW, et al: Hospital safety climate and its relationship with safe work practices and workplace exposure incidents. Am J Infect Control 28:211-221, 2000

43. Taylor C, Graham J, Potts H, et al: Impact of hospital consultants' poor mental health on patient care. Br J Psychiatry 190:268-269, 2007 
AUTHORS' DISCLOSURES OF POTENTIAL CONFLICTS OF INTEREST

\section{Relationships Between Managerial and Organizational Practices, Psychological Health at Work, and Quality of Care in Pediatric Oncology}

The following represents disclosure information provided by authors of this manuscript. All relationships are considered compensated unless otherwise noted. Relationships are self-held unless noted. I = Immediate Family Member, Inst = My Institution. Relationships may not relate to the subject matter of this manuscript. For more information about ASCO's conflict of interest policy, please refer to www.asco.org/rwc or ascopubs.org/op/authors/author-center.

Open Payments is a public database containing information reported by companies about payments made to US-licensed physicians (Open Payments).

Virginie Gandemer

Travel, Accommodations, Expenses: Jazz Pharmaceuticals, EUSA Pharma

No other potential conflicts of interest were reported. 